\title{
Numerical Analysis of the Shock Efforts on the Stress Level in the Dental Prosthesis Elements
}

\author{
Djebbar $\mathbf{N}^{1 *}$, Serier $\mathrm{B}^{2}$, Benbarek $\mathrm{S}^{2}$ and Bachir Bouiadjra $\mathrm{B}^{2}$ \\ ${ }^{1}$ Department of Mechanical Engineering, University of Burgundy, France \\ ${ }^{2}$ Department of Mechanical Engineering, University of Sidi-Bel-Abbes, Algeria
}

\begin{abstract}
The aim of this analysis was to determine the intensity and distribution of the stress in the components of the dental prosthesis (abutment, implant and bone) as a result of the shock efforts. This numerically study by finite element method was conducted in three zones (proximal, median, and distal) of these components.
\end{abstract}

Keywords: Dental implant; Bone; Efforts of shock; Finite element method

\section{Introduction}

The term "osseointegration" defined as the "direct structural and functional connection between ordered, living bone and the surface of a load-carrying implant at the light microscopic level [1]. Osseointegration is the term used worldwide in the dental specialties to describe the goal of implant treatment. Dr. Branemark's first use of implants (which he originally called "fixtures") to support dental prostheses was in beagle dogs [2]. The finite element method (FEM) plays an important role today in solving engineering problems in many fields of science and industry and can also be successfully applied in the simulations of biomechanical systems and dental implants [3]. The simulation with the help of the Finite Element Analysis (FEA) allows for taking the key features into the consideration: like material in homogeneity, anisotropy and changeability of mechanical properties of material as well as a very complicated geometry, boundary and load conditions [4]. Lin et al. developed a systematic protocol to assess mandibular bone remodeling induced by dental implantation, which extends the remodeling algorithms established for the long bones into dental settings [5]. In this study, a 3D model for a segment of a human mandible was generated from CT scan images, together with a titanium implant embedded to the mandible. The results examined the changes in bone density and stiffness as a result of bone remodeling over a period of 48 months. Resonance frequency analysis was also performed to relate natural frequencies to bone remodeling. The density contours are qualitatively compared with clinical follow-up X-ray images, thereby providing validity for the bone remodeling algorithm presented in dental bone analysis.

Static, dynamic and fatigue behaviours of the implant are investigated in this study [6]. Dynamic loads in 5 min applied on occlusal surface. Fatigue life the implant calculated based on Goodman, Soderberg, Gerber and mean-stress fatigue. Li et al. created a 3D finite element model for continuous variation of implant diameter and length, there by identifying their optimal range in type IV bone under biomechanical consideration [7]. Implant diameter ranged from 3.0 to $5.0 \mathrm{~mm}$, and implant length ranged from 6.0 to $14.0 \mathrm{~mm}$. The results suggest that under axial load, the maximum Von Mises stress in cortical and cancellous bones decrease by $50 \%$ and $27 \%$, respectively; and under buccolingual load, by $52 \%$ and $60 \%$, respectively. Under these two loads, the maximum displacements of implant-abutment complex decrease by $39 \%$ and $43 \%$, respectively. Goswami et al. determined the average insertion torque being applied to the dental implant while surgically placing it with a non-calibrated manual ratchet [8]. Simsek and Erkmen [9] studied the evaluation of the tensile and compressive stress for the cortical and cancellous bone under load conditions according to the distance inter-implants, inter-implant distance of 1.0 $\mathrm{cm}$ is the optimum distance for the two fixtures implantation. Koca et al. determined the amount and localization of functional stresses in implants and adjacent bone locations when the implants were placed in the posterior maxilla in proximity to the sinus using finite element analysis (FEA) [10]. However, Verri et al. analyzed the biomechanical interactions of a singular implant-supported prosthesis of different crown heights under vertical and oblique force, using the 3-D finite element method [11]. Six 3-D models were designed with Invesalius 3.0, Rhinoceros 3D 4.0, and Solidworks 2010 software. Each model was constructed with a mandibular segment of bone block, including an implant supporting a screwed metal-ceramic crown.

The finite element analyses of Alkan et al. led to demonstrate the increase or decrease for the maximum calculated stress values in preloaded screws after occlusal loads, these maximum stress values were well below the yield stress of both abutment and prosthetic screws of 2 implant systems tested [12]. The results imply that the 3 implant to abutment joint systems tested may not fail under the simulated occlusal forces. Biomechanical interaction between osseointegrated dental implants and bone is numerically investigated through 3D linearly elastic finite element analyses, when static functional loads occur [13] Influence of some mechanical and geometrical parameters on bone stress distribution is highlighted and risk indicators relevant to critical overloading of bone are introduced. Insertions both in mandibular and maxillary molar segments are analyzed, taking into account different crestal bone loss configurations. Verri et al. evaluated stress distribution in the fixation screws and bone tissue around implants in single-implant supported prostheses with crowns of different heights $(10,12.5,15 \mathrm{~mm}$ - crown-to-implant ratio 1:1, 1.25:1, 1.5:1, respectively) [14]. It was designed using three 3-D models. Each model was developed with a mandibular segment of bone block including an

${ }^{*}$ Corresponding author: Djebbar N, Department of Mechanical Engineering University of Burgundy, France, Tel: +33380 395000; E-mail: djebbarnour@yahoo.fr

Received November 04, 2017; Accepted January 07, 2018; Published January 14,2018

Citation: Djebbar N, Serier B, Benbarek S, Bouiadjra BB (2018) Numerical Analysis of the Shock Efforts on the Stress Level in the Dental Prosthesis Elements. Ind Eng Manage 7: 241. doi:10.4172/2169-0316.1000241

Copyright: @ 2018 Djebbar N, et al. This is an open-access article distributed under the terms of the Creative Commons Attribution License, which permits unrestricted use, distribution, and reproduction in any medium, provided the original author and source are credited. 
internal hexagon implant supporting a screw-retained, single metalceramic crown. The crown height was set at $10,12.5$, and $15 \mathrm{~mm}$ with crown-to-implant ratio of $1: 1,1.25: 1,1.5: 1$, respectively. The applied forces were $200 \mathrm{~N}$ (axial) and $100 \mathrm{~N}$ (oblique). The increase of crown height showed differences with the oblique load in some situations. By von Mises' criterion, a high stress area was concentrated at the implant/fixation screw and abutment/implant interfaces at crown-toimplant ratio of 1:1, 1.25:1, 1.5:1, respectively. Wang et al. created an accurately dimensioned finite element model with spiral threads and threaded bores included in the implant complex, positioned in a bone model, and to determine the magnitude and distribution of the force transformation/stress/strain patterns developed in the modeled implant system and bone and, thus, provide the foundational data for the study of the dynamic loading of dental implants prior to any external loading [15]. Cyclic axial and transverse loads, is studied by means of Finite Element shakedown analyses [16]. The unilateral contact conditions existing at the interfaces between the various parts of the implant, which depend on the degree of tightening of the internal screw connecting the abutment to the fixture of the implant, make it impossible to apply in a straightforward way the classical shakedown theorems. We illustrate a way of reasoning which allows the combination of shakedown analyses results with considerations about the contact conditions. Shakedown envelopes associated to several values of the internal screw tightening can be constructed; these suggest that a common implant design is not fully safe against cyclic loading conditions.

The purpose of this study was to investigate the effect of the shock effort on the stress distribution in component of the dental prosthesis, using three dimensional and finite element (FE) analysis. The stress distribution is analysed in the proximal, medial and distal zones in the interface bone-implant junction.

\section{Geometrical Model}

The three-dimensional geometrical model of the dental structure, illustrated in Figure 1, to achieve this goal the computer simulations involving the finite element code ABAQUS code version 6.11 was applied. The bone was modelled as full structure (block of bone with size equal to the section of lower jaw: $24.23 \mathrm{~mm}$ height and 17.43 $\mathrm{mm}$ width). It is composed of a spongy center surrounded by $2 \mathrm{~mm}$ of cortical bone. The implant is presented in form of screw of length $14 \mathrm{~mm}$ and diameter $4.1 \mathrm{~mm}$. Abutment of conical form is adjusted to the implant. The sizes of the abutment are: length $\mathrm{l}=7.2 \mathrm{~mm}$, lower diameter $\mathrm{d}_{1}=2.6 \mathrm{~mm}$ and great diameter $\mathrm{d}_{2}=3.6 \mathrm{~mm}$ [17].

Table 1 gives the elastic properties of the components of the

\begin{tabular}{|c|c|c|c|}
\hline Material & $\begin{array}{c}\text { Young's modulus, } \mathbf{E} \\
\text { (MPa) }\end{array}$ & $\begin{array}{c}\text { Poisson } \\
\text { ratio, v }\end{array}$ & Source \\
\hline $\begin{array}{c}\text { Implant (Titanium alloy } \\
\text { Ti-6Al-4V) }\end{array}$ & 110000 & 0.32 & {$[6,18]$} \\
\hline $\begin{array}{c}\text { Abutement (Titanium alloy } \\
\text { Ti-6Al-4V) }\end{array}$ & 110000 & 0.32 & {$[6,18]$} \\
\hline Cortical bone & $\begin{array}{c}\mathrm{E}_{\mathrm{x}}=\mathrm{E}_{\mathrm{Y}}=11500, \mathrm{E}_{\mathrm{Z}}=17000 \\
\mathrm{G}_{\mathrm{xY}}=3600, \mathrm{G}_{\mathrm{xz}}=\mathrm{G}_{\mathrm{Yz}}=3300\end{array}$ & $\begin{array}{c}\mathrm{U}_{\mathrm{xy}}=0.51, \\
\mathrm{U}_{\mathrm{xz}}= \\
\mathrm{U}_{\mathrm{yz}}=0.31\end{array}$ & {$[6,19]$} \\
\hline Cancellous bone & 2.13 & 0.3 & {$[6,18]$} \\
\hline
\end{tabular}

Table 1: Materials properties [17].

dental prosthesis [18]. The behaviour of the cortical bone is supposed orthotropic.

\section{Finite Element Model}

The mesh of the components is simplistic and consists of linear tetrahedron elements with four nodes (Figure 2). Since the interface of bone-implant experiences the largest deformations under load, it is necessary to mesh this boundary into small elements.

The implant system and the bone are meshed with increasingly larger elements as the distance from the interface increases, with the size of elements in contact with the interface being defined by the elements of the boundary mesh. The mesh of the components is verified for use in a finite element stress analysis.

\section{Load Conditions}

A tightening torque abutment-implant and implant-bone of 3500 $\mathrm{N} / \mathrm{mm}$ and a friction coefficient of 0.28 were retained [17,20,21]. Stress of $6 \mathrm{MPa}$ was applied to the structure according to the directions illustrated in Figure 3 [17,21,22]. This mechanical shock exerted on the bone and abutment following an accident the patient.

\section{Analysis Results}

\section{Shock effort exerted on the abutment}

In this study, the distribution of the equivalent stress in the dental prosthesis components (abutment, implant and bone) is illustrated in Figure 4, as a result of mechanical shock.

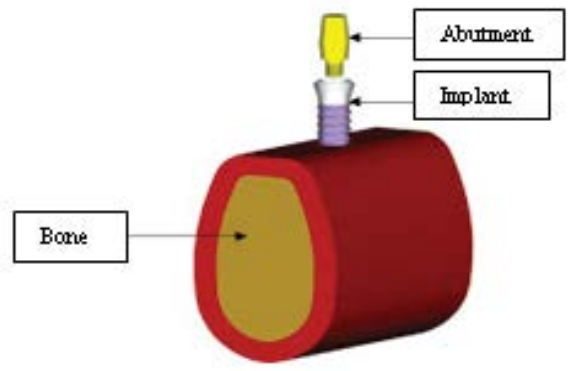

Figure 1: Three-dimensional model of the structure.

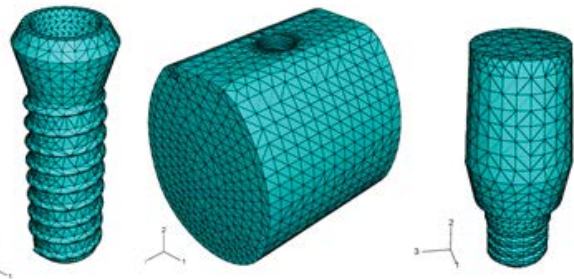

Figure 2: Finite element model.

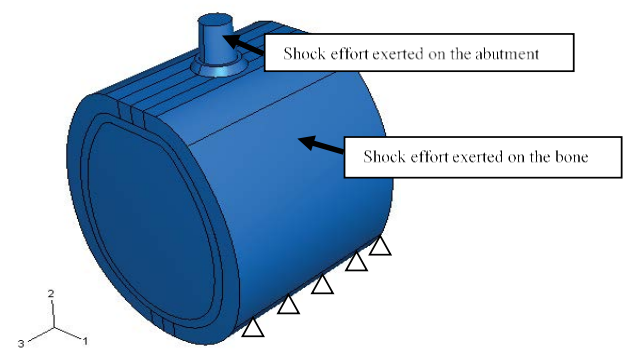

Figure 3: Boundary conditions of the model. 
This figure shows the level of the Von Mises stress in the three components of structure under the effect of a shock effort exerted perpendicular to the axis of the implant. The equivalent stress is highly concentrated on the living parts of the abutment in the region of abutment-implant fixation. The other zones are weak requested; top of the abutment is subjected by weak stress (Figure 4a).

A very heterogeneous distribution of equivalent stress along the implant, the intensity is largely higher than that generated in abutment. The upper part of the implant is the seat of high stress concentration. The stress is intensively localized in the region of contact implantabutment. In other parts of this component of the structure, the stress is almost uniformly distributed and its level remains weak (Figure 4b).

A shock effort applied to the surface of the abutment induced equivalent stress in the bone along the contact zone of the living body with the implant (Figure 4c). The highest stress level is observed on the sides of the organ in its proximal zone. The level of stress induced in the bone is relatively high and may constitute a risk of fracture of this element. The fracture stress of the bone is largely exceeded; this type of loading is dangerous to the stability of the structure.

\section{Shock effort exerted on the bone}

The results obtained from this analysis are illustrated in Figure 5. The latter shows the distribution of equivalent stress of Von Mises in the abutment, implant and bone under the effect of a shock effort exerted on the bone. The equivalent stress is highly concentrated on the living parts of the abutment (Figure 5a). The other zones are slightly requested.

In this part, the highly stress is located on the middle of the implant. The intensity decreases gradually as one move away from this zone.
The middle zone is the seat of stress concentration (Figure $5 b$ ). This type of effort puts the middle zone of the bone under high stress. The stress recorded in the bone is a very intensity and may lead to a risk of damage per notch effect (thread of the bone) (Figure 5c).

\section{Analysis of the Equivalent Stress}

\section{Along the implant and the bone}

For the development of this study we analyzed the behavior of the stress in the two components of the dental prosthesis (implant, bone) under effect of mechanical effort amplitude $6 \mathrm{MPa}$ exerted on the side face of the bone and the abutment. This type of loading may simulate an effort of shock applies to the structure. The distribution of the stress resulting from this analysis is represented in Figures 6 and 7. Stress was determined from the top to the bottom of the structure.

Figure 6 shows the variation of the equivalent stress, depending on the component undergoing the mechanical shock, along the implant. The most significant stress in the implant is located on the middle zone, where the shock is applied on the bone. Far from this zone, the stress tends to relax completely. The application part of effort is the seat of stress concentration. A mechanical shock exerted on abutment involves a stress concentration on the top of the implant this can be due to the good contact between the abutment and the implant. The level of the stress in the implant is extremely high and this some is the component undergoing the mechanical shock. It can reach a critical level by notch effect. Indeed, the threads of the implant are the seat of stress concentration.

A shock effort applied to the bone induced equivalent stress on the middle part about twenty twice more important than that exerted
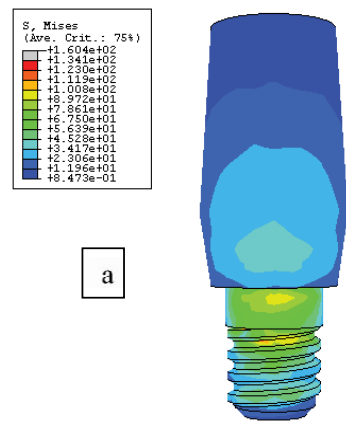
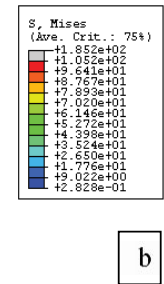
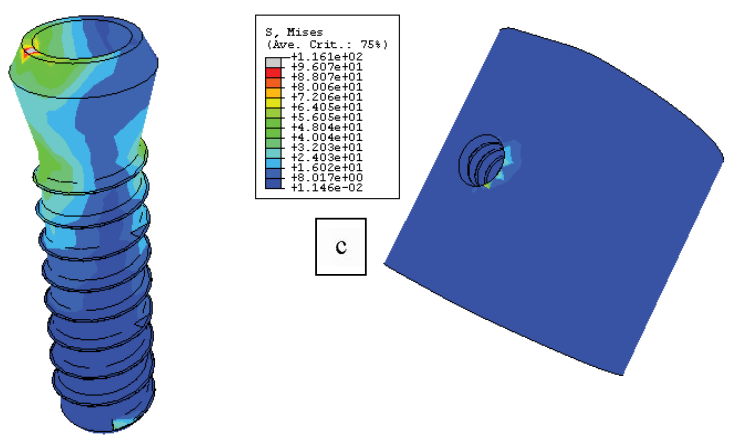

Figure 4: Stress distribution in the abutment, implant and bone.

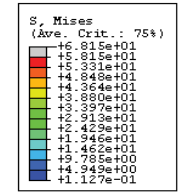

a

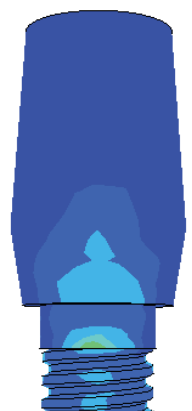

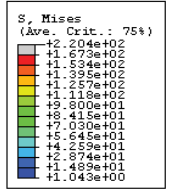
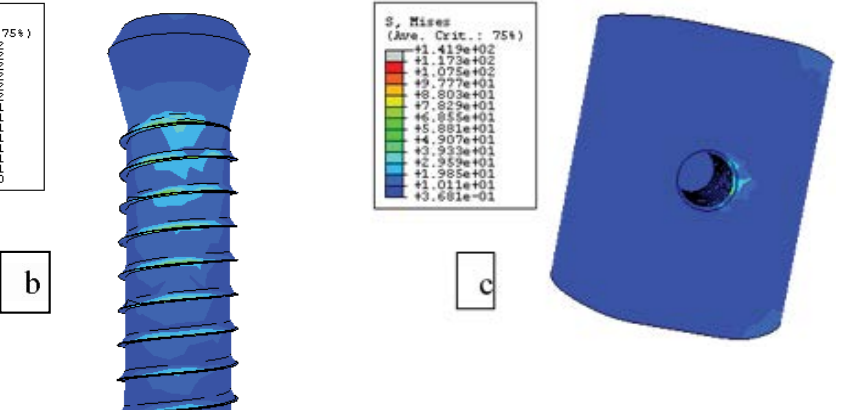

Figure 5: Stress distribution in the abutment, implant and bone. 
on this body (Figure 7). The equivalent stress increases, decreases and then remains constant, its level gradually lowers surface towards to the bottom of the bone. The distribution of Von Mises stress in bone,

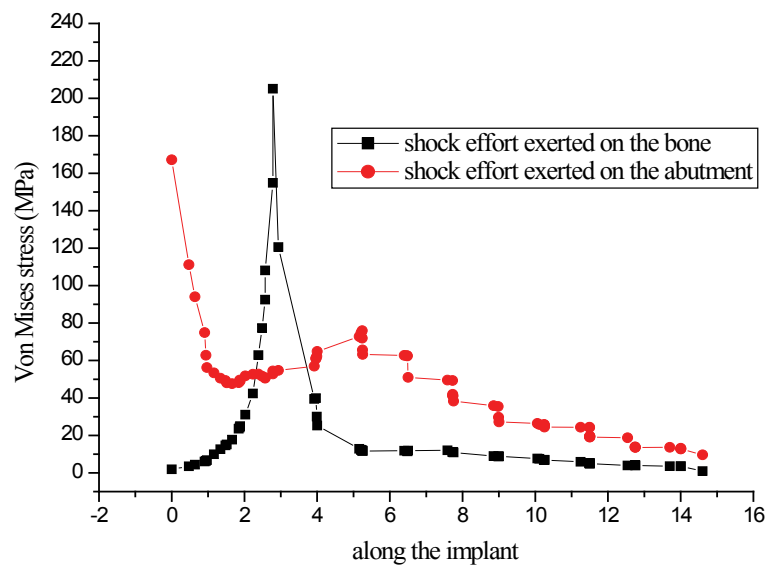

Figure 6: Variation of the equivalent stress along the implant.

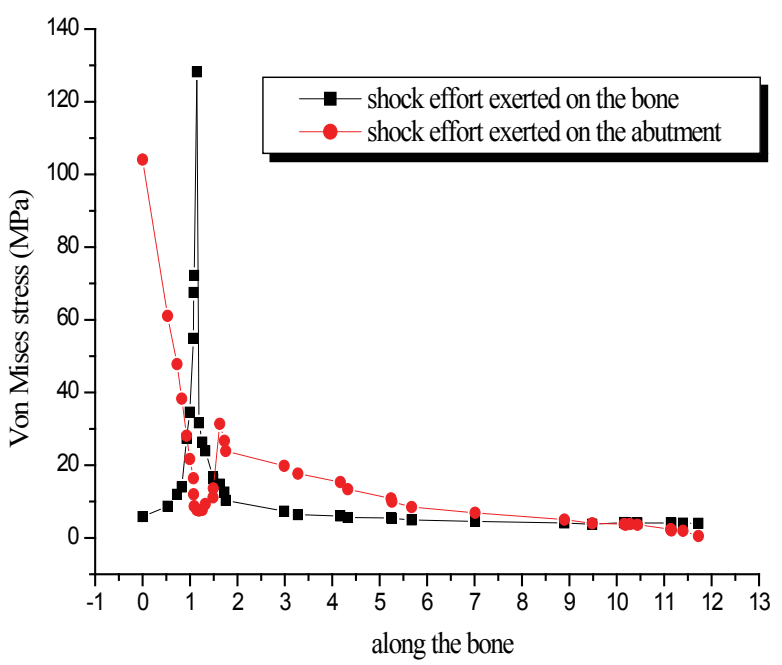

Figure 7: Variation of the equivalent stress along the bone. under the effect of a mechanical shock exerted on the abutment, is totally different from that induced by an effort exerted on the bone. Indeed, it has an intensity of more important stress on the proximal zone with two maxima (Figure 7). Its intensity is reach about time the stress applied to abutment. The level of the equivalent stress in the bone reaches a critical threshold able to involve the damage of the bone. Indeed, mechanical shock of this intensity can be fatal to this component. It may lead to the prosthesis loosening by fracture of the bone. Figures 6 and 7 show a mechanical shock exerted on abutment or the bone request virtually no bottom structure.

\section{Zones proximal, median and distal in the bone with interface bone-implant}

To better study the mechanical behavior of the dental prosthesis, an analysis of the distribution and intensity of the equivalent stress of Von Mises in three zones (proximal, medial and distal) in the bone in contact with the implant along helicoids was studied. The results of this analysis are illustrated in Figure 8. The latter represents the variation of the stress along the helicoid in these three zones in the bone near the bone-implant interface depending on the nature of the element undergoing mechanical shock.

\section{Proximal zone}

A mechanical shock applied to the abutment highly requests the proximal zone. The level of the equivalent stress in this zone decrease remains constant then increases along the helicoids. The distribution of this stress is almost symmetrical of the helicoids (Figure 8a). The stress induced in this part is very high intensity. They tend towards the failure stress to the traction of bone. Their amplitude may largely exceed the threshold of rupture of this component per effect notches at the bottom of stops sharp nets. This behavior differs from that given by a shock effort exerted on the bone. This last induced in the proximal zone of the stress of very weak intensity.

\section{Median zone}

In this part of the dental prosthesis a contrary behavior to the distribution of the equivalent stress is observed. Indeed, in this part the mechanical shock applied to the lateral side face of the bone induces higher stresses in the bone-implant interface (Figure $8 \mathrm{~b}$ ). Around the helicoid its distribution is almost symmetrical. It decrease, takes negligible values, and then increases to its initial value. Its level exceeds the limit of tensile failure of this body. A mechanical shock applied to the abutment practically does not request the medial zone of the bone.
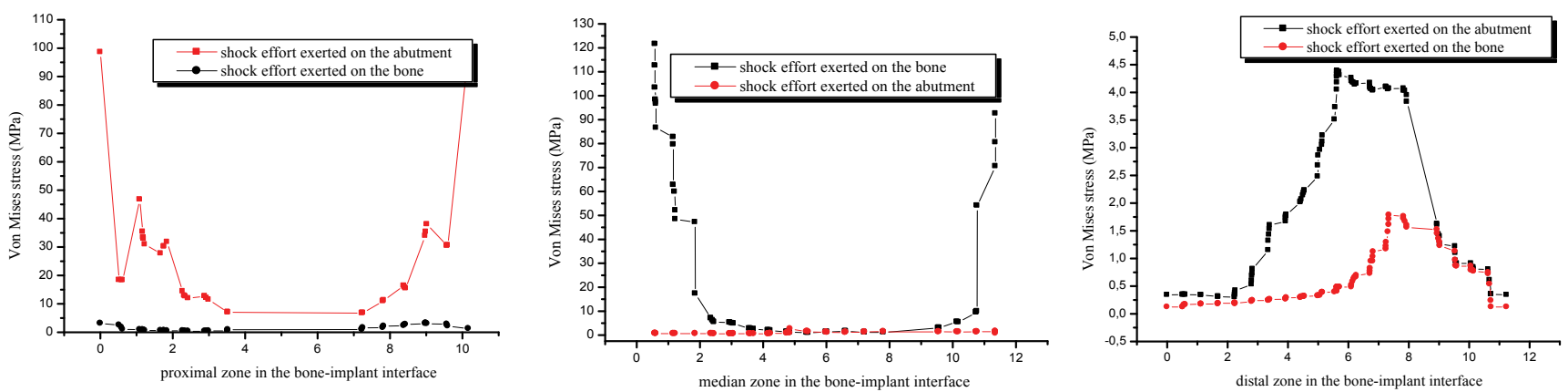

Figure 8: Variation of the equivalent stress in the bone-implant interface of three zone. 


\section{Distal zone}

The distribution of stress in the distal zone along the helicoid is illustrated in Figure 8c. The higher stresses are concentrated on the part of helicoid in which the contact implant-bone is very ultimate. This zone is far from that where the mechanical shock is applied, which explains the weak stress values recorded in this part and this some element of the structure undergoing this shock. The results obtained of this analysis show that a mechanical shock exerted on the side face of the bone, induced in this body in the vicinity of the interface with the implant, stress much greater than that applied to the abutment. The stresses located in the bone are largely higher than the threshold of failure may be fatal for the prosthesis.

\section{Conclusions}

Within the limitations of this study the following conclusions were drawn:

- A mechanical shock applied to side face of abutment generates highest stresses on the top of the structure. Their intensity decrease considerably in the near vicinity of this zone and cancels at its bottom.

- The level of stress varies considerably along the helical form of the implant and the bone. It is highest in the proximal zone of the structure.

- A load applied to the lateral surface of the bone, induces more significant stresses in the median zone of the structure. The other zones (proximal and distal) are weak requested.

- The equivalent stress of Von Mises in implant varies not only in the three zones proximal, median and distal but also along helicoid. The induced stress, under effect of such loading, in the elements of the dental prosthesis and particularly in the bone is very intense and may be fatal for the structure. An implant designed of resistant material can easily support the level of these stresses contrary with the bone, which is an alive material having of weak mechanical properties of resistance.

\section{References}

1. Brunski JB (1997) Implants in dentistry: essentials of endosseous implants for maxillofacial reconstruction. In: Block MS, Kent JN, Guerra $L$ editors. Philadelphia: Saunders, pp: 63-71.

2. Buser D, Weber HP, Donath K, Florellini JP, Paquette DW, Williams RC (1992) Soft tissue reactions to non-submerged unloaded titanium implants in beagle dogs. Journal of Periodontol 63: 226-236.

3. Bedzinski R (1997) Biomechanical Engineering, Publishing House Technical University of Wroclaw, Wroclaw.

4. Wierszycki W, Kakol W, Lodygowski T (2006) Numerical complexity of selected biomechanical problems. Journal of Theoretical and Applied Mechanics 44 797-818.

5. Lin D, Li Q, Li W, Duckmanton N, Swain M (2010) Mandibular bone remodeling induced by dental implant. The Journal of Biomechanics 43: 287-293.
6. Kayabasi O, Yuzbasioglu E, Erzincanli $F$ (2006) Static, dynamic and fatigue behaviors of dental implant using finite element method. Advances in Engineering Software 37: 649-658.

7. Li T, Kong L, Wang Y, Hu K, Song L, et al., (2009) Selection of optimal dental implant diameter and length in type IV bone: a three-dimensional finite element analysis. International Journal of Oral and Maxillofacial Surgery 38 : 1077-1083

8. Goswami CMM, Kumar CM, Vats CA, Bansal BAS (2013) Evaluation of dental implant insertion torque using a manual ratchet. Medical Journal Armed Forces India 6: 72-105.

9. Simsek B, Erkmen E (2006) Effects of different inter-implant distances on the stress distribution around endosseous implants in posterior mandible: A 3D finite element analysis. Journal of Medical Engineering \& Physics 28: 199-213.

10. Koca OL, Eskitascioglu G, Usumez A (2005) Three-dimensional finite-element analysis of functional stresses in different bone locations produced by implants placed in the maxillary posterior region of the sinus floor. The Journal of Prosthetic Dentistry 93: 38-44.

11. Verri FR, Batista VES, Santiago JF, Almeida DAF, Pellizzer EF (2014) Effect of crown to implant ratio on per implant stress: A finite element analysis. Materials Science and Engineering 45: 234-240.

12. Alkan I, Sertgoz A, Ekici B (2004) Influence of occlusal forces on stress distribution in preloaded dental implant screws. The Journal of Prosthetic Dentistry 91: 319-325

13. Baggi L, Cappelloni I, Maceri F, Vairo G (2008) Stress-based performance evaluation of osseointegrated dental implants by finite-element simulation. Simulation Modelling Practice and Theory 16: 971-987.

14. Verri FR, Santiago JF, Almeida DAF, Oliveira GBB, Batista VES, et al., (2015) Biomechanical influence of crown to implant ratio on stress distribution ove internal hexagon short implant: 3-D finite element analysis with statistical test. Journal of Biomechanics 48: 138-145.

15. Wang RF, Kang B, Lang LA, Razzoog ME (2009) The dynamic natures of implant loading. The Journal of Prosthetic Dentistry 101: 359-371.

16. Genna F, Shakedown (2004) Shakedown, Self-stresses, and unilatera contact in a dental implant problem. European journal of mechanics-A/Solids 23: 485-498.

17. Djebbar N, Serier B, Bouiadjra BB, Benbarek S, Drai A (2010) Analysis of the effect of load direction on the stress distribution in dental implant. Materials and Design 31: 2097-2101.

18. Wang C, Fu G, Deng F (2015) Difference of natural teeth and implantsupported restoration: A comparison of bone remodeling simulations. Journal of Dental Sciences 14: 1-11.

19. Ammar HH, Ngan P, Crout RJ, Mucino VH, Mukdadi OM (2011) Three dimensional modeling and finite element analysis in treatment planning for orthodontic tooth movement. Am J Orthod Dento Facial Orthop 139: 59-71.

20. Achour T, Merdji A, Bouiadjra BB, Serier B, Djebbar N (2011) Stress distribution in dental implant with elastomeric stress barrier. Materials and Design 32: 282-290.

21. Djebbar N, Serier B, Bouiadjra BB (2015) Finite element analysis in static and dynamic behaviors of dental prosthesis. Structural Engineering and Mechanics 55: 65-78

22. Djebbar N, Serier B, Bouiadjra BB (2017) Stress Distribution of the Variable Dynamic Loading in the Dental Implant: A Three-Dimensional Finite Element Analysis. Journal of Biomimetics, Biomaterials and Biomedical Engineering 31: 44-52. 